\title{
ASSESSMENT OF KEY DIMENSIONS AND DETERMINANTS OF WOMEN'S EMPOWERMENT IN BANGLADESH
}

\author{
Rajib Dey, Assistant Professor \\ Hajee Mohammad Danesh Science \& Technology University, Dinajpur, Bangladesh \\ Email: rajib dey2002@yahoo.com
}

Md. Mohsan Khudri, Assistant Professor

Department of Business Administration, Uttara University, Dhaka, Bangladesh

E-mail: mkhudri@isrt.ac.bd

\begin{abstract}
This study attempts to measure empowerment of women in Bangladesh context using the data extracted from 2011 Bangladesh Demographic and Health Survey (BDHS). Principal component analysis (PCA) is applied to variables pertaining to decision making and justification of physical violence by husband. Based on PCA, indices are constructed to capture two distinct dimensions of women's empowerment: attitudes towards domestic violence and participation in decision making. All the decision making variables have positive impact on women empowerment index considering the dimension participation in decision making whereas these variables (except decision regarding visits) have relatively low and negative impact on attitudes towards violence. On the contrary, all the variables regarding justification of beaten by husband have significant impact on attitudes towards domestic violence and low impact on decision making dimension of women empowerment. A set of socio-economic factors such as age group, division, level of education, employment status, religion, wealth index, and number of living children, contraceptive use and fertility preference are assessed with a view to identifying key determinants of women empowerment. The results revealed that highly educated women are more likely to protest against physical violence in comparison with illiterate women. Women from Sylhet are less empowered than that of other divisions.
\end{abstract}

\section{KEY WORDS}

Women empowerment; Principal component analysis; Logistic regression model.

According to Lord and Hutchison (1993), empowerment has been constructed on the basis of an uneven distribution of power among people which arises from people's experiences of power or powerlessness. There are several sources of power, such as personality, organizational, property, wealth, and class. Conger and Kanungo (1988) provided two definitions of empowerment. The first definition deems empowerment as "power over someone" and hence, it formulates empowerment as a relational construct, which argues for a dependency or interdependency relationship between people and is relationally constructed. The second definition considers empowerment as motivational construct, which argues for an urge among people for power and ability to influence and control other people. Women's empowerment is a complex term that captures a multitude of constructs: control of household resources and assets, decision making capabilities, position in society, and knowledge level. Since it is a multidimensional concept, it is not surprising that various definitions of the concept exist. United Nations Population Network (1995) defines women's empowerment as women having a conscious awareness of self value, an access to opportunities and resources, options and power to practice them, control over their own lives, and influence over their direction to social change. Kabeer (2001) stated that empowerment is the expansion of people's ability to make strategic life choices in a context where this ability was previously denied to them. According to Bennett (2002), empowerment is the enhancement of assets and capabilities of diverse individuals and groups to engage influence and hold the institutions accountable which affect them. As per Keller and Mbwewe (1991), women's empowerment is a process whereby women become able to organize themselves to increase their own self-reliance, to assert their independent right to make 
choices and control resources which will assist in challenging and eliminating their own subordination. Alsop et al. (2006) define empowerment as "the process of enhancing an individual's or group's capacity to make effective choices, that is, to make choices and then to transform those choices into desired actions and outcomes". Riley (1997) and Kishor (2000) also defined empowerment as the ability to make choices. Smith et al. (2003) define women's status as women's ability proportional to men. Three aspects of the definition of women's status are worth noting: Firstly, it is relative to men rather than absolute or relative to other women. Secondly, it is formed on the concept of power. Thirdly, the definition has both intra-household and extra-household dimensions and takes into account the influence of customs and norms that may dictate differential roles, acceptable behaviors, rights, privileges, and life options for women and men.

In Bangladesh, the scenario of women empowerment in household level is traditionally low. According to BBS (2011), the population of Bangladesh has reached 142,319 thousands. The total enumerated population comprises 71,255 thousand males and 71,064 thousand females, which yields a sex ratio of 100.3 indicating almost equal numbers of men and women abide in the country. Therefore, almost half of the population is women. Haque et al. (2011) observed that there prevails a mid-level of women empowerment but autonomy level of Bangladeshi women is absolutely low. BDHS (2011) demonstrated that women fall behind men owing to some critical factors, such as educational acquisition, literacy, employment, exposure to mass media, contribution to women's empowerment and exercising remarkable influence on the development of women's personality and on strengthening their position in the household and society in general. United Nations Development Program (UNDP) (2011) reported that Bangladesh ranks 112 out of 187 countries in context of Gender Inequality Index which implies a composite measure reflecting inequality in achievements between women and men in three dimensions: reproductive health, empowerment, and the labor market. Hausmann et al. (2011) stated that Bangladesh ranks 69 out of 135 countries in terms of gender equality reported in 2011 Gender Gap Index developed by world economic forum. Thus, based on both gender-related indices, Bangladesh took place in bottom half of countries included in each index. Thus, without considering empowerment of half of the population, sustainable economic development can't be achieved. Therefore, the full participation and partnership of both women and men are necessary in productive and reproductive life, including the sharing of responsibilities for the care and nurture of children as well as the maintenance of the household.

In accordance with Jejeebhoy (2000), the ability to make choices can be a function of several factors, such as women's economic decision making, child-related decision making, freedom of movement, power relations with their spouse, and access to and control over resources. Haque et al. (2011) mentioned that the level of women autonomy decreases with the increase of education whereas education increases the level of women empowerment but not smoothly. Kamal et al. (2006) found marital status and education as significant covariates of women empowerment in Bangladesh. The paper also specified that unmarried women were six times more likely to be empowered. Moreover, women having secondary education were 1.4 times more likely to be empowered than uneducated women. Women's current age, place of residence, education, religion, media exposure etc. are the important factors affecting women empowerment and their autonomy. The objectives of this study are to identify key dimensions of women's empowerment and investigate the relationship of these dimensions with socio-economic variables.

\section{DATA}

Data source. The data for this study were extracted from the 2011 Bangladesh Demographic Health Survey (BDHS) which was a sixth national demographic and health survey conducted throughout Bangladesh. The survey was conducted under the authority of the National institute for population research and training (NIPORT) of the Ministry of Health and Family Welfare of the Government of Bangladesh. BDHS 2011 provides detailed information on fertility, child mortality, child nutrition, fertility preferences, use of family 
planning method, knowledge and attitudes towards HIV/AIDS, other sexually transmitted infections (STI), women empowerment, domestic violence etc. BDHS 2011 used a two stage stratified sample (stratification is carried out at each division into urban and rural regions) from the 2011 census frame. The sample consists of 600 primary sampling unit (psu), among them 207 and 393 were selected from urban and rural areas, respectively. In second stage, 30 households were selected from each psu using systematic method. All married women (12-49 years) and men (15-54 years) who slept in the selected households the night before the survey were suitable for the female and male survey respectively. From a total of 17,964 selected households, 17,511 households were found to be occupied and among them 17,141 households were successfully interviewed. A total of 18,222 women of aged 12-49 were identified in these households, among them 17,842 women were interviewed with 98 percent response rate. Of the 4343 eligible men belonging to age group 15-54, 3997 (92 percent) were successfully interviewed.

Data and variables. In this study, we used the information about women's decisions regarding their own health care, child health care, large household purchases and visits to her family or relatives. In addition, we have taken information regarding women's attitudes towards domestic violence by husband is justified if wife burns the food, argues with him, goes out without telling him, neglects the children and refuses to have sexual intercourse with him. Some other indicators such as division, type of place of residence, age group, education, wealth index, number of living children, fertility preferences, employment status, belonging to organization and watching TV/ listening to radio/ music were assessed to determine whether these factors have significant impact on dimensions of women's empowerment.

\section{METHODOLOGY}

Principal component analysis (PCA). PCA is a multivariate statistical technique used to describe the variation of a set of multivariate data in terms of a set of uncorrelated linear combinations of variables (Khudri and Chowdhury, 2013). It can extract as many as there are variables. However, it does not serve the purpose of variables reduction, and only components which explain a good proportion of overall variance and have an intuitive interpretation, are usually extracted for subsequent use in regression analysis (Johnson and Wichern, 1982).

Let $X_{1}, X_{2}, \ldots, X_{p}$ be $p$ variables measured in $n$ women have the covariance matrix $\Sigma$ with eigenvalues $\lambda_{1} \geq \lambda_{2} \geq \ldots \geq \lambda_{p} \geq 0$ and $Y_{1}, Y_{2}, \ldots, Y_{p}$ be the $p$ principal components which are uncorrelated linear combinations of the original variables, $X_{1}, X_{2}, \ldots, X_{p}$. Consider the linear combinations:

$$
\begin{aligned}
& Y_{1}=a_{11} X_{1}+a_{12} X_{2}+\ldots+a_{1 p} X_{p} \\
& Y_{2}=a_{21} X_{1}+a_{22} X_{2}+\ldots+a_{2 P} X_{p} \\
& Y_{p}=a_{p 1} X_{1}+a_{p 2} X_{2}+\ldots+a_{p p} X_{p}
\end{aligned}
$$

This equation system can be expressed as $Y=a^{\prime} X$ where $Y^{\prime}=\left(Y_{1}, Y_{2}, \ldots, Y_{p}\right), X^{\prime}=\left(X_{1}\right.$, $\left.X_{2}, \ldots, X_{p}\right)$ and $a$ is the matrix of coefficients. The coefficient of the first principal component, $a_{11}, \ldots, a_{1 p}$, are chosen in such a way that $\operatorname{Var}\left(Y_{1}\right)=a_{1}^{\prime} \Sigma a_{1}$ is maximized subject to the constraint that $a_{11}^{2}+\cdots+a_{1 p}^{2}=1$ (Johnson and Wichern, 1982). The variance of this component is equal to $\lambda_{1}$, the largest eigenvalue of $a^{\prime}$. The second principal component is completely uncorrelated with the first component and has variance equal to $\lambda_{2}$; this component explains additional but less variation in the original variable than the first component, subject to the same constraint. Further, principal components (up to the maximum of $p$ ) can be defined in the same manner. Each principal component is uncorrelated with the rest of the components and the sum of squares of its coefficients equals one. After performing PCA, factor scores of the first two principal components would 
be used to develop the women indices. It points out that new factors have linear correlation with original variables.

Logistic regression model. Let, $\mathrm{X}=\left(\mathrm{x}_{1}, \mathrm{x}_{2}, \ldots, \mathrm{x}_{\mathrm{p}}\right)^{\prime}$ be a vector of $\mathrm{p}$ covariates ( or independent variables). The basic form of logistic regression model is then:

$$
P(y=1 \mid x)=\pi\left(x_{i}\right)=\frac{\exp \left(x_{i} \beta\right)}{1+\exp \left(x_{i} \beta\right)}=P(x)
$$

where: $\alpha$ is a scale parameter and $\beta$ is a $p \times 1$ vector parameter. $P(x)$ represents the probability that given by:

$$
P(y=0 \mid x)=1-\pi\left(x_{i}\right)=\frac{1}{1+\exp \left(x_{i} \beta\right)}=1-P(x)
$$

Then a well-known transformation of $\mathrm{P}(\mathrm{x})$ known as logit transformation is defined as

$$
\begin{array}{r}
g\left(x_{i}\right)=\operatorname{logit}\left[\pi\left(x_{i}\right)\right]=\log \left[\frac{\pi\left(x_{i}\right)}{1-\pi\left(x_{i}\right)}\right]=x_{i} \beta, \\
\text { or } g\left(x_{i}\right)=\beta_{0}+\beta_{1} x_{i 1}+\beta_{2} x_{i 2}+\cdots \cdots \cdots+\beta_{k} x_{i k} .
\end{array}
$$

The coefficients are used to compute odds ratios (OR), which give the ratio of two odds of occurring an event $(Y=1)$. An odds ratio more than 1 indicates a positive association between the independent and dependent variables and an odds ratio less than 1 indicates a negative association. Odds ratio equals to 1 indicating there is no association between the variables. The logistic regression technique can be used not only to identify the risk factors but also to predict the probability of success.

\section{RESULTS AND DISCUSSIONS}

Women empowerment indices in attitudes towards spousal violence and in decision making.

Table 1 - KMO and Bartlett's Test

\begin{tabular}{l|lc}
\hline \multicolumn{2}{c}{ KMO Measure of Sampling Adequacy. } & .790 \\
\hline \multirow{3}{*}{ Bartlett's Test of Sphericity } & Approx. Chi-Square & $4.477 \mathrm{E} 4$ \\
& df & 36 \\
& Sig. & .000 \\
\hline
\end{tabular}

According to Kaiser (1974), a sample with a KMO (Kaiser-Meyer-Olkin) value greater than 0.5 is acceptable for performing factor analysis. The results displaying in Table 1 demonstrate that the KMO measure of sampling adequacy coefficient was 0.79 in this case, the data may be said to be appropriate for factor analysis. The Bartlett's test derived the significance level as 0.00 which indicated that the data were suitable for running factor analysis. The results displaying in Table 2 indicate that the first two components yield eigen values 2.736 and 2.532 respectively, which are merely greater than unity and together they explain 58.5 percent of total variation in the original variables.

Table 2 - Eigen Value and Variance Explained by the First Two Principal Components

\begin{tabular}{ccc}
\hline Component & Eigen value & \% of variance \\
\hline 1 & 2.736 & 30.40 \\
2 & 2.532 & 28.13 \\
\hline
\end{tabular}


Each component except the first two explains a decreasing proportion of variance afterwards. Since the first two principal components were employed in the construction of women empowerment index, eigen values and variance explained by the rest of the components are not exhibited in the following table. Principal component analysis with varimax rotation was performed on the survey data to explore the relationships among the distinct women empowerment variables and identify which individual variables of empowerment belong together. Table 3 reports the estimated factor loadings on different variables used in this study. The results shown in Table 3 suggest that attitudes towards violence (Factor 1 ) and participation in decision making (Factor 2) are two major factors of women empowerment.

Table 3 - Results of principal Component Method with Varimax Rotation

Factor loadings

\begin{tabular}{lcc}
\hline \multicolumn{1}{c}{ Variables } & Factor 1 & Factor 2 \\
\hline Decisions regarding own health care & .004 & .788 \\
Decisions regarding large household purchases & .001 & .835 \\
Decisions regarding visits to relatives & .045 & .842 \\
Decisions regarding child health care & -.007 & .729 \\
Beating justified if wife goes out without informing husband & .754 & .006 \\
Beating justified if wife neglects the children & .776 & .000 \\
Beating justified if wife argues with her husband & .763 & .025 \\
Beating justified if wife refuses having sex with husband & .725 & .005 \\
Beating justified if wife burns food & .654 & .010 \\
\hline
\end{tabular}

Each respondent was asked whether she believed the use of physical violence was justifiable in the following situations: if she (1) goes out without informing husband, (2) neglects the children, (3) argues with her husband, (4) refuses sex, and (5) burns food. These five variables constitute the first dimension of women empowerment which is named as attitudes towards violence. It is assumed that women justifying physical violence for the reasons aforementioned are likely to be living in households where the balance of power between spouses is skewed. Vindication for physical violence is indicative of a social structure that provides power to the husbands and assigns a very traditional and submissive role to women simultaneously, which could, in turn, lead to more frequent episodes of violence against women. Another dimension, participation in decision making comprises four decision making variables: decisions regarding respondent's health care, large household purchases, visits to relatives, and child health care.

Table 4 shows factor scores of each variable which indicates the impact of that variable whether positive or negative impact on women empowerment. It is observed that decisions regarding own healthcare, child healthcare, visits to relatives and large household purchases have positive factor scores in context of participation in decision making which implies that all these variables have positive impact on this dimension of women empowerment. On the contrary, except decisions regarding visits to relatives, rest of the decision making variables have negative impact on the another dimension of women empowerment, that is, attitudes towards violence. In the context of second dimension, decision regarding visits to relatives has got the highest score (.329) indicating significant impact on participation in decision making. All the variables pertaining to justification of beaten by husband are said to have significant impact on attitudes towards violence and beating is justified if wife neglects the children has got the highest score which means it plays vital role in this dimension of women empowerment. In contrast, these variables have relatively low impact on another dimension of women empowerment.

A weighted average score for factor 1 - attitudes towards violence is constructed for each woman using the loadings (given in table 3 ) of factor 1 as weight and it is called women empowerment index in attitudes towards violence. In the final regression model, this is 
grouped into two categories on the basis of median of weighted average of women- low and high attitudes towards violence.

Table 4 - Results of Factor Scores of Variables

Factor Scores

\begin{tabular}{lcc}
\hline \multicolumn{1}{c}{ Variables } & $\begin{array}{c}\text { Attitudes Towards } \\
\text { Violence }\end{array}$ & $\begin{array}{c}\text { Participation in } \\
\text { Decision Making }\end{array}$ \\
\hline Decisions regarding own health care & -.006 & .308 \\
Decisions regarding large household purchases & -.008 & .327 \\
Decisions regarding visits to relatives & .008 & .329 \\
Decisions regarding child health care & -.010 & .285 \\
Beating justified if wife goes out without informing husband & .278 & -.005 \\
Beating justified if wife neglects the children & .287 & -.008 \\
Beating justified if wife argues with her husband & .282 & .002 \\
Beating justified if wife refuses having sex with husband & .268 & -.005 \\
Beating justified if wife burns food & .242 & -.003 \\
\hline
\end{tabular}

Similar work was done for factor 2: participation in decision making with a view to constructing women empowerment index in decision making context. Then this is grouped into two categories- low and high decision making in the final regression model.

Logistic regression for women empowerment in attitudes towards spousal violence. Binary logistic regression analysis is performed in this study in order to determine whether the predictor variables such as respondent's age, division, education, wealth index, number of living children, contraceptive use, and occupation have significant impact on women empowerment in context of justification of physical violence.

Table 5 - Estimates of Logistic Regression of Women Empowerment in Attitudes towards Violence

\begin{tabular}{|c|c|c|c|c|c|c|}
\hline \multirow[b]{2}{*}{ Covariates } & \multirow[b]{2}{*}{$\mathrm{B}$} & \multirow[b]{2}{*}{ S.E. } & \multirow[b]{2}{*}{ P-value } & \multirow[b]{2}{*}{ OR } & \multicolumn{2}{|c|}{$95 \%$ C.I. for OR } \\
\hline & & & & & Lower & Upper \\
\hline \multicolumn{7}{|l|}{ Age Group } \\
\hline $15-19(\mathrm{RC})$ & - & - & - & - & - & - \\
\hline $20-24$ & .026 & .064 & .689 & 1.026 & .904 & 1.164 \\
\hline $25-29$ & -.046 & .068 & .501 & .956 & .837 & 1.091 \\
\hline $30-34^{c}$ & -.130 & .073 & .076 & .878 & .760 & 1.014 \\
\hline $35-39^{c}$ & -.132 & .078 & .091 & .877 & .752 & 1.021 \\
\hline $40-44$ & -.053 & .081 & .509 & .948 & .810 & 1.110 \\
\hline $45-49$ & .108 & .087 & .212 & 1.114 & .940 & 1.320 \\
\hline \multicolumn{7}{|c|}{ Administrative Division } \\
\hline Sylhet (RC) & - & - & - & - & - & - \\
\hline Barishal $^{\mathrm{a}}$ & .254 & .068 & .000 & 1.289 & 1.128 & 1.473 \\
\hline Chittagong $^{\mathrm{D}}$ & .122 & .062 & .050 & 1.129 & 1.000 & 1.275 \\
\hline Dhaka $^{\mathrm{a}}$ & .306 & .062 & .000 & 1.358 & 1.203 & 1.534 \\
\hline Khulna $^{\mathrm{a}}$ & .261 & .064 & .000 & 1.298 & 1.144 & 1.472 \\
\hline Rajshahi $^{a}$ & -.282 & .064 & .000 & .754 & .664 & .856 \\
\hline Rangpur $^{\mathrm{a}}$ & .459 & .066 & .000 & 1.583 & 1.392 & 1.801 \\
\hline \multicolumn{7}{|c|}{ Level of Education } \\
\hline Illiterate (RC) & - & - & - & - & - & - \\
\hline Primary & -.031 & .045 & .491 & .969 & .887 & 1.059 \\
\hline Secondary & .022 & .050 & .658 & 1.022 & .926 & 1.128 \\
\hline Higher $^{a}$ & .375 & .078 & .000 & 1.455 & 1.249 & 1.694 \\
\hline Religion & & & & & & \\
\hline
\end{tabular}




\begin{tabular}{|c|c|c|c|c|c|c|}
\hline Non Muslim (RC) & - & - & - & - & - & - \\
\hline Muslim ${ }^{a}$ & -.312 & .053 & .000 & .732 & .659 & .812 \\
\hline \multicolumn{7}{|l|}{ Wealth Index } \\
\hline Poorest (RC) & - & - & - & - & - & - \\
\hline Poorer & .078 & .054 & .148 & 1.081 & .973 & 1.202 \\
\hline Middle $^{\mathrm{a}}$ & .232 & .055 & .000 & 1.261 & 1.133 & 1.404 \\
\hline Richer $^{a}$ & .278 & .055 & .000 & 1.320 & 1.185 & 1.470 \\
\hline Richest $^{\mathrm{a}}$ & .522 & .060 & .000 & 1.686 & 1.500 & 1.895 \\
\hline \multicolumn{7}{|l|}{ Living Child } \\
\hline No Child (RC) & - & - & - & - & - & - \\
\hline Child between $1 \& 2^{a}$ & -.597 & .066 & .000 & .550 & .483 & .626 \\
\hline Having Child $3+^{a}$ & -.742 & .076 & .000 & .476 & .410 & .553 \\
\hline \multicolumn{7}{|l|}{ Contraceptive Use } \\
\hline Not Using (RC) & - & - & - & - & - & - \\
\hline Using a Method ${ }^{a}$ & .256 & .035 & .000 & 1.292 & 1.206 & 1.385 \\
\hline \multicolumn{7}{|l|}{ Employment Status } \\
\hline Unemployed (RC) & - & - & - & - & - & - \\
\hline Employed $^{\mathrm{a}}$ & -.170 & .048 & .000 & .844 & .768 & .927 \\
\hline Constant & .562 & .099 & .000 & 1.755 & & \\
\hline
\end{tabular}

RC: Reference category, ${ }^{a} p<.01,{ }^{b} p<.05 ;{ }^{c} p<.1$

Age group is found to be statistically insignificant in this case at $5 \%$ level of significance (Table 5). All the divisions except Chittagong have significant impact on women empowerment. The odds ratio indicate that women in Barishal (OR: 1.289), Dhaka (OR: 1.358), Khulna (OR: 1.298) and Rangpur (OR: 1.583) are more likely not to justify the physical violence than women in Sylhet. In case of education, highly educated women are more likely to protest against physical violence in comparison with illiterate women. As per results reported in Table-5, religion, contraceptive use and respondent's education play significant role in women empowerment. Women who are Muslim and employed had less chance to protest against physical assault than Non-Muslim and unemployed counterparts respectively. Women having children between 1 and 2 or more than 3 had less likelihood of not justifying this issue compared to women having no child. In contrast, women who use contraceptive are more likely to believe that beaten by husband is not justified. Results also reveal that among the categories of wealth index women belonging to richest, richer, and middle family are $1.686,1.320$, and 1.261 times more likely respectively not to justify physical violence comparing to that of poorest family.

Logistic regression for women empowerment in decision making. Binary logistic regression was employed again to evaluate the impact of predictors on women empowerment in context of household decision making. Age plays crucial role in women empowerment taking this dimension into account.

Table 6 indicates that the likelihood of getting priority in decision making goes up with the increase in age. Among the divisions, only Rajshahi is found to be insignificant. It is observed that women abiding in Barishal (OR: 1.494), Chittagong (OR: 1.179), Dhaka (OR: 1.282), Khulna (OR: 1.347), and Rangpur (OR: 1.880) are more likely to participate in decision making in comparison with women belonging to Sylhet. Results also disclose that women who stay in urban area and have higher education are 1.387 and 1.795 times more likely to get the privilege of participation in decision making compared to rural and illiterate women respectively. The probability of participating in decision making is more for Muslim women than Non-Muslims.

According to different categories of wealth index, richer and middle class women are less likely to participate in decision making comparing to women coming from poorest family. Women of richest and poorer categories are observed to be insignificant for this study. Women having child between 1 and 2 or more than 3 tend to participate in decision making 
than women having no children. Those of the women watch TV or listen radio are 1.156 times more likely to play role in decision making compared to women who don't have attachment to this aforementioned media of entertainment. Employed females are supposed to be more conscious than unemployed ones and result reflect the same.

Table 6 - Estimates of Logistic Regression of Women Empowerment in Decision Making

\begin{tabular}{|c|c|c|c|c|c|c|}
\hline \multirow[b]{2}{*}{ Covariates } & \multirow[b]{2}{*}{$\mathrm{B}$} & \multirow[b]{2}{*}{ S.E. } & \multirow[b]{2}{*}{ P-value } & \multirow[b]{2}{*}{ OR } & \multicolumn{2}{|c|}{$95.0 \%$ C.I. for OR } \\
\hline & & & & & Lower & Upper \\
\hline \multicolumn{7}{|l|}{ Age Group } \\
\hline $15-19(\mathrm{RC})$ & - & - & - & - & - & - \\
\hline $20-24^{a}$ & .263 & .071 & .000 & 1.301 & 1.131 & 1.496 \\
\hline $25-29^{a}$ & .716 & .075 & .000 & 2.046 & 1.765 & 2.372 \\
\hline $30-34^{a}$ & .939 & .082 & .000 & 2.558 & 2.176 & 3.006 \\
\hline $35-39^{a}$ & 1.060 & .087 & .000 & 2.887 & 2.432 & 3.427 \\
\hline $40-44^{a}$ & .963 & .090 & .000 & 2.619 & 2.194 & 3.125 \\
\hline $45-49^{a}$ & .774 & .096 & .000 & 2.168 & 1.796 & 2.616 \\
\hline \multicolumn{7}{|l|}{ Administrative Division } \\
\hline Sylhet (RC) & - & - & - & - & - & - \\
\hline Barishal $^{a}$ & .402 & .071 & .000 & 1.494 & 1.300 & 1.717 \\
\hline Chittagong $^{a}$ & .165 & .065 & .011 & 1.179 & 1.039 & 1.338 \\
\hline Dhaka $^{a}$ & .249 & .064 & .000 & 1.282 & 1.130 & 1.455 \\
\hline Khulna $^{\mathrm{a}}$ & .298 & .067 & .000 & 1.347 & 1.182 & 1.535 \\
\hline Rajshahi & .036 & .067 & .594 & 1.036 & .909 & 1.182 \\
\hline Rangpur $^{\mathrm{a}}$ & .631 & .068 & .000 & 1.880 & 1.645 & 2.149 \\
\hline \multicolumn{7}{|l|}{ Place of Residence } \\
\hline Rural (RC) & - & - & - & - & - & - \\
\hline Urban $^{a}$ & .327 & .041 & .000 & 1.387 & 1.280 & 1.503 \\
\hline \multicolumn{7}{|l|}{ Level of Education } \\
\hline Illiterate (RC) & - & - & - & - & - & - \\
\hline Primary $^{a}$ & .141 & .047 & .003 & 1.151 & 1.051 & 1.261 \\
\hline Secondary ${ }^{a}$ & .266 & .052 & .000 & 1.305 & 1.177 & 1.446 \\
\hline Higher $^{a}$ & .585 & .081 & .000 & 1.795 & 1.531 & 2.105 \\
\hline \multicolumn{7}{|l|}{ Religion } \\
\hline Non Muslim (RC) & - & - & - & - & - & - \\
\hline Muslim $^{\mathrm{a}}$ & .139 & .054 & .010 & 1.150 & 1.034 & 1.278 \\
\hline \multicolumn{7}{|l|}{ Wealth Index } \\
\hline Poorest (RC) & - & - & - & - & - & - \\
\hline Poorer & -.090 & .056 & .106 & .914 & .819 & 1.019 \\
\hline Middle $^{\mathrm{a}}$ & -.185 & .058 & .001 & .831 & .742 & .931 \\
\hline Richer $^{a}$ & -.208 & .061 & .001 & .812 & .720 & .916 \\
\hline Richest $^{c}$ & -.136 & .070 & .054 & .873 & .761 & 1.002 \\
\hline \multicolumn{7}{|l|}{ Living Children } \\
\hline No Child (RC) & - & - & - & - & - & - \\
\hline Child between $1 \& 2^{a}$ & 1.735 & .084 & .000 & 5.671 & 4.814 & 6.680 \\
\hline Having Child $3+^{a}$ & 1.601 & .094 & .000 & 4.957 & 4.123 & 5.959 \\
\hline Table 6 (Continuation) & & & & & & \\
\hline
\end{tabular}

\begin{tabular}{|c|c|c|c|c|c|c|}
\hline \multirow[b]{2}{*}{ Covariates } & \multirow[b]{2}{*}{ B } & \multirow[b]{2}{*}{ S.E. } & \multirow[b]{2}{*}{ P-value } & \multirow[b]{2}{*}{ OR } & \multicolumn{2}{|c|}{$95.0 \%$ C.I. for OR } \\
\hline & & & & & Lower & Upper \\
\hline \multicolumn{7}{|l|}{ Fertility Preference } \\
\hline Have Another (RC) & - & - & - & - & - & - \\
\hline Undecided & -.120 & .147 & .413 & .887 & .665 & 1.183 \\
\hline No More ${ }^{a}$ & .211 & .048 & .000 & 1.234 & 1.123 & 1.357 \\
\hline
\end{tabular}




\begin{tabular}{|c|c|c|c|c|c|c|}
\hline Sterilized & .079 & .082 & .334 & 1.082 & .922 & 1.270 \\
\hline Declared In fecund & .033 & .119 & .780 & 1.034 & .818 & 1.307 \\
\hline \multicolumn{7}{|c|}{ Belonging to Organization } \\
\hline No (RC) & - & - & - & - & - & - \\
\hline Yes $^{c}$ & .060 & .036 & .098 & 1.062 & .989 & 1.139 \\
\hline \multicolumn{7}{|c|}{ Watching TV/ Listening Radio/Music } \\
\hline No $(\mathrm{RC})$ & - & - & - & - & - & - \\
\hline$Y_{e s}{ }^{a}$ & .145 & .042 & .001 & 1.156 & 1.064 & 1.255 \\
\hline \multicolumn{7}{|l|}{ Employment Status } \\
\hline Unemployed (RC) & - & - & - & - & - & - \\
\hline Employed $^{a}$ & .500 & .052 & .000 & 1.648 & 1.490 & 1.824 \\
\hline Constant & -3.060 & .119 & .000 & .047 & & \\
\hline
\end{tabular}

RC: Reference category, ${ }^{a} p<.01 ;{ }^{b} p<.05 ;{ }^{c} p<.1$

\section{CONCLUDING REMARKS}

In this study we have developed two important dimensions of women empowerment namely attitudes towards spousal violence as well as decision making at household level. The logistic regression model identified different factors those have significant influence on women empowerment. Some potential socio-economic risk factors like division, education, occupation, wealth index, religion and number of living children are identified as key determinants of empowerment. Education is supposed to play a vital role in empowerment of women. The results also revealed that highly educated women are more likely to protest against physical violence in comparison with illiterate women. The administrative division has been found statistically significant and women from Sylhet division are less empowered than that of other divisions of Bangladesh. Respondent's occupational status is significantly associated with empowerment in decision making and employed women are more likely to participate in decision making at household level than unemployed women. Hence, it can be concluded that if the women achieve higher degree of education and become employed, the likelihood of being empowered will gradually increase.

\section{REFERENCES}

1. Alsop, R., Bertelsen, M., and Holland, J. 2006. Empowerment in Practice from Analysis to Implementation. Washington, DC: World Bank.

2. BBS. 2011. Population \& Housing Census 2011- Preliminary Results: Bangladesh Bureau of Statistics, Statistics Division, and Ministry of Planning. Dhaka, Bangladesh.

3. BDHS. 2011. Bangladesh Demographic and Health Survey 2007: National Institute of Population Research and Training (NIPORT), Mitra and Associates, and Macro International. Dhaka, Bangladesh and Calverton, Maryland, USA.

4. Bennett, L. 2002. Using Empowerment and Social Inclusion for Pro-poor Growth: A Theory of Social Change. Working Draft of Background Paper for the Social Development Strategy Paper, Washington, DC: World Bank.

5. Conger, J., \& N. Kanungo. 1988. The Empowerment Process: Integrating Theory and Practice. Academy of Management Review, 13 (2), 471-482.

6. Haque, M. M., T. M. Islam, M. I. Tareque, and M. G. Mostofa. 2011. Women Empowerment or Autonomy: A Comparative View in Bangladesh Context. Bangladesh eJournal of Sociology, vol. 8, no. 2, 17-30.

7. Hausmann, R., L. D. Tyson, and S. Zahidi. 2011. The Global Gender Gap Report: Ranking and Scores. Geneva. Switzerland: World Economic Forum.

8. Jejeebhoy, S. J. 2000. "Women's Autonomy in Rural India: Its Dimensions, Determinants, and the Influence of Context", in H. Presser and G. Sen, (eds) Women's Empowerment and Demographic Processes: Moving Beyond Cairo; New York: Oxford University Press. 
9. Johnson, R. A., and D. W. Wichern. 1982. Applied Multivariate Statistical Analysis. Prentice Hall, New Jersey, USA, pp. 484-513.

10. Kabeer, N. 2001. Reflections on the Measurement of Women's Empowerment in Discussing Women's Empowerment-Theory and Practice, SIDA Studies no 3. Stockholm: Swedish International Development Cooperation Agency.

11. Kamal, N., and K. M. Zunaid. 2006. Education and Women's Empowerment in Bangladesh. Working Paper 11. Bangladesh: Centre for Health, Population, and Development (CHPD), Independent University.

12. Keller, B., and D. C. Mbwewe. 1991. Policy and Planning for the Empowerment of Zambia's Women Farmers. Canadian Journal of Development Studies 12(1), 75-88.

13. Khudri, M.M. and Chowdhury, F. 2013. Evaluation of Socio-economic status of households and identifying key determinants of poverty in Bangladesh. European Journal of Social Sciences 37(3): 377-387.

14. Kishor, S. 2000. Empowerment of Women in Egypt and Links to the Survival and Health of Their Infants. In Women's Empowerment and Demographic Processes, edited by $\mathrm{H}$. Presser and G. Sen, 119-158. Oxford: Oxford University Press.

15. Lord, J. and P. Hutchison. 1993. The Process of Empowerment: Implications for Theory and Practice. Canadian Journal of Community Mental Health, 12(1), 5-22.

16. Riley, N. 1997. Gender, Power, and Population Change. Population Bulletin 52(1), 2- 46.

17. Smith, L. C., U. Ramakrishnan, A. Ndiaye, L. J. Haddad, and R. Martorell. 2003. The Importance of Women's Status for Child Nutrition in Developing Countries. Washington, DC: International Food Policy Research Institute.

18. UNPN. 1995. Report of the Fourth World Conference on Women, Bejing, New York: United Nations.

19. UNDP. 2011. Human Development Report 2011. New York: Oxford University Press. 